\title{
Romper el espejo: la mujer y la trasgresión de código en la literatura rumana
}

\author{
Lavinia-Alexandra DRAGOTă \\ Universidad Complutense de Madrid \\ ladragot@ucm.es
}

\begin{abstract}
RESUMEN
El objetivo de este trabajo es el estudio de la imagen de la mujer en la literatura rumana, especialmente durante la Segunda Guerra Mundial, teniéndose en cuenta la escasez de estudios sobre el tema y el interés que presenta. Para ello, averiguamos cómo describe la literatura de esta época las relaciones entre hombres y mujeres, cómo presenta y representa ambos géneros y, en especial, cuál es el papel de los personajes femeninos, qué funciones ejercen, de qué manera son mostrados y mirados. A través de los personajes femeninos de la novela de Cella Serghi, Cartea Mironei (El Libro de Mirona) realizamos un análisis de la imagen de la mujer con el fin de visibilizar su evolución en la literatura y, por consecuencia, en la sociedad rumana de la Segunda Guerra Mundial.
\end{abstract}

Palabras clave: literatura rumana, imagen de la mujer, Segunda Guerra Mundial, género, personajes femeninos, evolución, sociedad.

\section{Breaking the mirror: women and the transgression of code in the Romanian literature}

\begin{abstract}
The objective of this work is the study of the image of women in Romanian literature, especially during World War II, taking into account the scarcity of studies on the subject and the interest it presents. We find out how the literature of this period describes the relations between men and women, how presents and represents both genders and, especially, what is the role of the female characters, which functions exercised, how they are looked and described. Through the female characters of Cella Serghi's novel, Cartea Mironei (The Book of Mirona) we analyze the image of women in order to visualize their evolution in literature and, consequently, in the Romanian society of Second World War.
\end{abstract}

Keywords: Rumanian Literature, the image of women, World War II, Gender, Female Characters, Evolution, Society. 


\section{Rumanía y la Segunda Guerra Mundial: un acercamiento}

El periodo de entreguerras marca un antes y un después en la historia de Rumania. Esta etapa de grandes cambios se sitúa a continuación de la historia moderna y constituye una primera fase en la historia rumana contemporánea. Aunque su inicio está marcado por los actos de unificación del país en 1918, es difícil apuntar a una fecha que marque su final. El momento de auge en cuanto a evolución económica es el año 1938, mientras que, si nos referimos a la situación general del estado, tenemos que señalar el año 1940. Este último, trae consigo grandes acontecimientos como la caída de las fronteras, la instauración del régimen dictatorial de Ion Antonescu y la firma del Pacto Tripartito. Como consecuencia del Pacto, Rumanía acompaña a Alemania en las operaciones contra la URSS, pero pese a la ayuda alemana, sufre un gran número de bajas por la poca preparación militar de su ejército.

Desde 1941 hasta 1944 el ejército rumano se constituye en el mayor contingente de los países del Eje, desplegados en los territorios de Moldavia, Transnistria y Ucrania. Después de la derrota de Alemania en el Frente del Este, ante la contraofensiva de las tropas soviéticas, el Ejército Rojo alcanza la frontera rumana en la primavera de 1944. Unos meses más tarde, el 23 de agosto de 1944, Antonescu es detenido por orden del Rey Mihai I y se forma un nuevo gobierno de coalición cambiando de bando. De esta manera, se facilita el rápido avance soviético por los Balcanes y Rumanía lucha contra el Eje hasta la capitulación alemana.

El periodo 1918-1940 es el único en la historia moderna y contemporánea del país en que Rumanía no está dividida. La expresión periodo de entreguerras no se puede entender solo desde un punto de vista cronológico, sino que, se tiene que estudiar a través de las consecuencias que tiene en la sociedad rumana. Así pues, para hablar de cultura no nos podemos estancar en el año 1939, y tampoco en el 1940. Para hablar de la evolución de la cultura y la literatura tenemos que incluir numerosos logros que han tenido lugar entre 1940 y 1944 y, más tarde, entre 1944 y 1947. Estos logros son el resultado de actos caracterizados por el espíritu del periodo de entreguerras.

\section{Cella Serghi y Cartea Mironei}

El espíritu del periodo de entreguerras se define por las convulsiones y compromisos sociales, la recuperación y relanzamiento económico, pero, sobre todo, por el inmenso enriquecimiento de la vida cultural rumana. Todos estos aspectos sociales impregnan un carácter particular a la literatura de esta época. Muchos son los escritores que destacan por su labor literario durante estos años, pero quiero señalar el de Cella Serghi, una de las escritoras que, a pesar de todos los obstáculos del sistema político, consigue romper los esquemas de la tradición literaria rumana.

Una de las características de esta tradición literaria es asociar el rol femenino con la sensibilidad, la emoción, el recato, la reproducción, lo sumiso y lo privado; y el rol masculino al poder, a lo público, a la creación y al conocimiento. Sin embargo, esto no se cumple en la literatura de Cella Serghi. De origen hebrea, nace en 1907 en Cons- 
tanta, y muere en Bucarest en 1992. Representante de la literatura rumana de entreguerras, fue también publicista y traductora. Su nombre real es Cella Marcoff, adoptando como seudónimo Serghi, por el nombre de su abuelo Serghi Marcoff, de origen búlgaro. La escritora sentirá durante toda su vida una fuerte atadura emocional con su ciudad natal, con la infancia, pero sobre todo con el mar. La separación de este lugar de ensueño a causa de la llegada de la guerra y la necesidad de refugiarse, deja profundas huellas en la niña Cella. La nostalgia del mar y la amargura de esta separación son una constante en su vida y muchas veces también en sus obras.

Cella Serghi estudia derecho en Bucarest y se gradúa en 1931. Trabaja durante una temporada como abogada, experiencia que le ayuda a conocer una gran variedad de caracteres y enriquecer el abanico de sus personajes. Escribe reportajes y crónicas teatrales para distintos periódicos y empieza a gozar de gran éxito. Sin embargo, hasta 1937, año en el pública Panza de păianjen (La telaraña), novela que aparece con la recomendación de tres de los grandes escritores de la literatura rumana -Liviu Rebreanu, Camil Petrescu y Mihail Sebastian- no empieza su carrera literaria. Con Panza de păianjen, Cella Serghi crea un modelo de escritura femenina en la literatura rumana -modelo centrado en un personaje femenino, subjetivo y narcisista, y que aboga por el derecho de la mujer a ser feliz:

Creo que la literatura femenina es especial. Se trata de una literatura con una voz distinta, con otra sensibilidad; es la voz que habla y quiere ser escuchada. La mujer defiende otras cosas. Defiende la libertad de cultivarse, de moverse, de ser feliz y de ser igual en posibilidades al varón. Por todos estos derechos, tan naturales, ella ha tenido que luchar y esta lucha se respira en su literatura.

Durante un tiempo vive en Paris, dónde continúa con la escritura y la lectura en un grupo de estudiantes rumanos, dato que incorpora más tarde en su novela que se titula (Se caen los muros) Cad zidurile (1950) en su primera edición y en ediciones posteriores (1965) Cartea Mironei (El libro de Mirona) o simplemente Mirona (1972); novela que sitúa los hechos en los años de la Segunda Guerra Mundial. El cambio que sufre desde la aparición de la primera edición es considerable. En cada edición Cella Serghi añade detalles que en ediciones anteriores no podía revelar debido a la censura política. Existe una gran evolución de la protagonista y del desarrollo de los hechos de una edición a otra, pues en la primera novela conocemos a una chica tímida, enamorada y soñadora mientras que en la última edición sale a la luz la mujer comprometida social y políticamente. La imagen final con la que el lector se queda tras la lectura de la novela es la imagen de un periodo histórico caracterizado por grandes transformaciones.

Todos los personajes femeninos de Cella Serghi están destinados a una vida inquietante y cautivadora, tienen un mundo interior muy complejo y siguen caminos tortuosos en su lucha por la afirmación social. Cartea Mironei (El libro de Mirona) es, según la autora, una denuncia social:

Yo he vivido en una época en la que tenías que luchar por cada año de escolarización o por derechos que hoy nos parecen naturales como derechos de las mujeres. Para que 
estos derechos se conviertan en realidad, aboqué por ello en cada uno de mis libros; en cada uno he combatido el apoliticismo en el que se había acostumbrado a vivir la mujer, sin participar en todo aquello que atormentaba el mundo.

Mirona Runcu, una chica de diecinueve años, personaje principal y al mismo tiempo narradora, es una joven que cree en su destino como escritora. En una conferencia en el Instituto Francés de Bucarest, Mirona conoce a Stefan, un hombre maduro, inteligente y encantador, pero casado. Al enterarse de que está escribiendo una novela (que al final será la propia historia que estamos leyendo), la invita al cenáculo. De esta manera, Mirona conoce un mundo diferente que alimenta su fascinación por Stefan. Al principio proyecta su amor por él a través de un profundo idealismo, sin embargo, después de años de espera y de haber vivido la guerra y sus horrores, Mirona comprende que Stefan es un cobarde.

Crece en una familia con un ritmo matriarcal, pues su bisabuela -la vieja Caţiandomina con autoridad indiscutible una casa oscura, cerrada y misteriosa, llena de mujeres infelices-. En este ambiente opresivo, Mirona encuentra refugio en los libros. Destaca por un profundo espíritu independiente y emancipado y sueña con llegar a ser libre de las ataduras sociales. Decide irse a Paris a estudiar derecho y conoce de primera mano el entorno de los grupos socialistas comprometidos con los actos de apoyo de la lucha republicana en España. Este ambiente, tan diferente del conocido, hace que su vuelta a Rumanía y la llegada de la Segunda Guerra Mundial al país produzcan profundos cambios en su manera de ver y entender el mundo. Hay varios capítulos -enlazados de manera ingeniosa- que proporcionan detalles aterradores por su realismo sobre los estragos de la guerra, la tragedia de los mutilados de los hospitales de la Cruz Roja y los horrores de los campos de exterminación nazi. Sin embargo, lo que provoca el cambio irreversible en Mirona es la muerte- al final de la guerra- de su amiga Lisandra, una luchadora comunista que había sacrificado toda su vida por sus ideales.

Este final es un nuevo comienzo. Mirona decide alejarse definitivamente de su anterior vida -Stefan, su familia, pero sobre todo de su indiferencia hacia la política del país y hacia el concepto de justicia-. Se compromete con los ideales sociales, culturales y políticos de su amiga Lisandra y sale, finalmente, del estado latente de apoliticismo en el que se encontraba. Aunque el germen de la mujer nueva existía en Mirona antes de la llegada de la guerra, esta ha hecho que despierte de un sueño letárgico. El final de su proceso de maduración es una prueba de su lucha contra las limitaciones impuestas por la sociedad y contra el modelo tradicional de la mujer en la época.

A modo de conclusión, cito las palabras de Rosa Montero en la «Introducción» de Historias de mujeres:

Quiero decir que media humanidad, la parte femenina, ha vivido durante milenios una existencia a menudo clandestina y en gran medida olvidada, pero siempre mucho más rica que la horma social en que estaba atrapada, siempre por encima de los prejuicios y los estereotipos. Porque hay una historia que no está en la historia y que sólo se puede rescatar aguzando el oído y escuchando los susurros de las mujeres. 


\section{Referencias bibliográficas}

Montero, Rosa (1997): Historias de mujeres. Alfaguara, Madrid.

PIRU Alexandru (2001): Istoria literaturii române. Editura „Grai şi Suflet - Cultura Naţională», Bucureşti.

Pop, Marius (1976): Convorbiri cu Cella Serghi, în revista Orizont, an XXVII, nr. 41, 14 octombrie 1976, pag. 1.

SERghi, Cella (2008): Cartea Mironei. Editura Litera Internațional, Jurnalul Național.

Serghi, Cella (2008): Pânza de păianjen, cu o postfaţă de autoare, Editura Cărţile Tango.

Serghi, Cella (2013): Pe firul de păianjen al memoriei. Editura Polirom, Bucureşti. 